\title{
Challenges and barriers perceived by paravets and veterinarians in delivery of minor- veterinary services at farmers' door- step: An exploratory study in four States of India
}

\author{
Vikash Kumar and HR Meena \\ Received: 24 November 2020 / Accepted: 10 February 2021 / Published online: 07 June 2021 \\ (C) Indian Dairy Association (India) 2021
}

\begin{abstract}
Delivery of animal health service is unique in India in the term that it is delivered by both paravets and veterinarians and in the complementary and supplementary relationship sometimes, with co-ordination and also independently. Paravets are very low in educational qualification and training, with improper execution of their roles and responsibilities with desired accuracy and accountability. The present study was conceptualized to assess the challenges and barriers in the delivery of minor- veterinary services at farmers' door- step from the perspective of trainers of paravet school (veterinarians) as well as paravet themselves. The research was carried under an exploratory research design, in which a random sampling method was used to reach out to the respondents. Key issues in decisionmaking regarding livestock extension and veterinary services (based on guidelines issued by DFID) as perceived by veterinarians were identified. Results indicated that lack of information booklets on breeding and management, substandardized curriculum and limited skills in diagnosis, lack of regular training programmes, and ethical issues with role obligations were prioritized challenges. Trainers agreed that multiple issues were plaguing delivery of animal health service as obtained $R B Q$ values which were not showing a wide variation. Hence interventions should be planned with a wider focus to resolve these constraints plaguing the delivery of minor veterinary services.
\end{abstract}

Dairy Extension Division, ICAR- National Dairy Research Institute, Karnal-132 001, Haryana, India

Vikash Kumar $(\square)$

Dairy Extension Division, ICAR- National Dairy Research Institute, Karnal-132 001, Haryana, India

Email:vkshkmr70@gmail.com
Keywords: Animal health service (AHS), Accountability, Barriers, Challenges, DFID, Rank-based quotient (RBQ), Pareto Analysis

\section{Introduction}

The main challenge inefficient delivery of animal health services in India can be stated as shortage of veterinarians (Channappagouda and Sasidhar, 2018; Sasidhar and Reddy, 2013), and lack of adequate skills as well as knowledge among the staff of the State Department of Animal Husbandry (Shubeena et al. 2019). In India, there exists a 49.00 percent gap between veterinarians working at field level against their total requirement (Agrawal et al. 2013). The delivery of animal health services in India has been constrained by a lack of collaboration and coordination among the organizations responsible for the service delivery. Thus, it could be imperative to increase the number of veterinarians, paravets, development of linkages with the State Department of Animal Husbandry and Dairying (Rao et al. 2015). Paravets could be a liaison between farmers, service providers, and professionals upstream. The need is more in private than public due to the expansion of veterinary services in the private sector (Rama et al., 2011). Strengthening of existing mobile veterinary clinics for a wider area coverage of animal health service on demand and encouragement for public-private participation in livestock service delivery could help improve the reach and quality of livestock services (Channappagouda and Sasidhar, 2018).

There exists a need for a paradigmatic shift in the delivery of animal health services by service providers in India that qualification of paravets should be based more on output and outcome of learning rather than relying on input supply only. The curriculum should be standard and harmonized for all the states. There is also an urgent need for monitoring of paraveterinary services for which trained paravets should be registered for their efficient monitoring. More than 100 countries of the world are in process of developing a national qualification framework for paravets. European Qualification framework, ASEAN Qualification Reference Framework, and Southern African Development Community are few examples of it (Barbaruah, 2019). Linking veterinarians with their auxiliary 
(paravets), for veterinarians the coverage of a larger area, increased sales of medicines, better knowledge of the area, better coverage of the area, etc. could be a potential challenge that needs to be addressed. For these para- professional auxiliaries, proper technical assistance, counseling, training, delivery of quality inputs need to be ensured. The regulatory quality should presume that the activities of the paravets should be controlled by veterinary services so that, for example, Paravets whose competencies are inadequate or who provide counterfeit products should be banned from practice. In practice, the veterinary services, in general, do not have the means of exercising this control. The control must be delegated to veterinarians present in the field (Saadi and Isabelle, 2015).

When the distance from state animal health service (AHS) centers to farmer's doorstep increases, the preference of farmers for animal health providers shifted towards private practitioners rather than government service providers. When farmers were in good socioeconomic condition with owing a greater number of crossbred cattle, they preferred to avail themselves the animal health services provided by government veterinarians. The farmer having good socio-economic conditions prefer veterinarians over paravets and other animal health delivery channels because they could pay the high transaction cost of veterinarians over paravets (Mirajkar et al. 2011). Paravets provide flexible and cost-effective services to resource-poor farmers in marginalized and remote areas which remain untouched by public veterinary services. Keeping this in mind, policy-makers should consider recognizing this pro-poor approach in favor of paravets (Warburton et al., 2011).

\section{Material and Methods}

\section{Study Area}

This study was conducted in four states of India namely, Uttar Pradesh, Haryana, Rajasthan, and Maharashtra. The selection of states for the study was based on the highest bovine population, Milk production, number of paravets schools. States namely, Uttar Pradesh, Rajasthan, and Maharashtra rank first, second and third in terms of the highest bovine population respectively (NDDB, 2015). Haryana ranks second in per capita milk availability (NDDB , 2019) and has progressive growth in dairying. These states show rich prospects in dairying due to high rural households, veterinary hospitals/ polyclinics, and AI done (DAHD\& F, 2018). Moreover, all four states belong to different agro-climatic zones, which provide soundness and validity to the study. In which, Haryana from trans- Gangetic plains, Uttar Pradesh from upper- Gangetic plains, Maharashtra from western plateau and hills, and Rajasthan from semi-arid eastern plains were selected for the study. Thus, dairying prosperous states from different agro-climatic zones represent the sampling adequacy. One district from each state was selected purposively constituting a total of four districts for the study. Hisar district from Haryana state, Mathura district from Uttar Pradesh, Jaipur district from Rajasthan state, and Ahmadnagar district from Maharashtra state were selected (19 ${ }^{\text {th }}$ Livestock Census, 2012). The selection of districts was based on the highest number of paravet schools as compared to other districts of the state.

\section{Selection of respondents and sampling methods}

Paravets and veterinarians (trainers of paravet schools) were surveyed to delineate the challenges and barriers in the delivery of minor- veterinary services by paravets. Those paravets were selected as respondents who have undergone at least 1-month of training for minor veterinary services rather than only trained for AI. They must be delivering their services at the farmer's doorstep for at least 2 years under the guidance/ consultation with veterinarians on a payment basis. Those Paravets were surveyed who were not working under any NGO such as J\& K Trust, BAIF, etc. The selection criteria for a trainer of paravet school (veterinarian) was that he/ she should be having at least more than one year of experience in that Paravet School at the time of the investigation. The exploratory research design was used in the study. A random sampling method was used to reach out to the respondents. A pilot study was conducted on a limited scale before interviewing the intended respondents to gain insight and preliminary information, based on which interview schedule could be planned and formulated. The pilot study was conducted in the Karnal district of Haryana by selecting 20 paravets. Based on qualitative inputs provided by respondents, the interview schedule was re-designed and modified accordingly.

\section{Statistical tools and techniques}

Based on focus group discussions, challenges and barriers to inefficient delivery of animal husbandry services by paravets at farmer's doorstep were identified. To prioritize these perceived challenges in the delivery of services from the perspective of paravets themselves, a "rank-based quotient" (RBQ) was used (Sabarathnam, 1988).

$$
R B Q=\sum \frac{i=\ln (F i)(n+1-i) \times 100}{N n}
$$

$\mathrm{Fi}=$ Frequency of paravets for the $\mathrm{i}^{\text {th }}$ rank of the problem.

$\mathrm{N}$ and $\mathrm{n}=$ Number of paravets and the maximum number of ranks given for various challenges by a paravets, respectively.

Pareto analysis technique was followed to delineate the barriers perceived by trainers of paravet schools inefficient delivery of para-veterinary services. In this analysis, it was hypothesized that 20 percent of the factors were causing 80 percent of the problems. This management technique tells whether 
by solving a few issues, major bottlenecks could be resolved or not.

\section{Results and Discussion}

\section{Key issues in decision making for delivery of animal health} services as perceived by veterinarians

Various issues such as privatization of animal health service, prospect and provision of cadres vis-à-vis job security, and consultancy role of animal health professionals affect the delivery of animal health service them as well as the selection of animal health service provider by the farmer. For the various types of service (curative, preventive, productive, and diagnostic), it was found that perceived importance given to preventive and productive services by farmers were most potent in affecting their choice for the service provider as perceived by 90.00 and 75.00 percent of farmers respectively for two types of services (Table 1). Thus, the results infer that most farmers have predetermined choices for service providers depending on their compatibility with socio-economic conditions and availability of services. Thus, interventions must attempt to maximize engagement of all socio-economic categories of farmers, paravets, and veterinarians (Hopker et al., 2018). For productive services, such as AI and PD, only 10.00 percent of farmers perceived it as the least potent choice affecting the choice of service provider because $\mathrm{AI}$ and $\mathrm{PD}$ were normally performed by paravets at their doorstep. However, 75.00 percent of respondents found it as most potent because of the level of satisfaction of farmers towards the productive services and quality of service rendered by service providers. A study conducted by Jain (2016) in the Tonk district of Rajasthan also revealed that 80.00 percent of farmers had medium satisfaction towards the delivery of health services. "Experience of livestock owners in animal husbandry and cultural values of farmer associated with livestock influence their willingness to pay for service" was found least potent by 73.33 and 96.67 percent veterinarians respectively. Delivery of services on integrated aspects as per the extent of crop-livestock interaction was also found least potent by 80.00 percent of veterinarians.

In the context of privatization of services, 81.67 percent of veterinarians perceived that appropriate time would be required for reforms of privatization (Table 1). The finding aligned with reporting of Barbaruah (2017) who revealed that paradigmatic shift should give more reliance on public-private partnership and privatized service delivery to increase accountability and overcome the shortage of veterinarians in India. The possible reason may be that, for sustainable development and coordination for the delivery of service and multi-stakeholder participation, paradigmatic changes require time and effort. Paravets consult veterinarians in case technical complexity and emergency occur at the field level which they could not handle with the prevailing level of knowledge and expertise. Livestock professionals should work in coordination with farmers, extension professionals to address challenges at the grass-root level. Para-veterinary services had very less focus on extension, outreach, ethical, and miscellaneous roles. About 40.00 percent of veterinarians perceived the least potency of preventive and productionoriented skills of vets in inducing privatization and neglecting other roles. Farmers mostly prefer paravets due to their low overhead and transaction cost, awareness of farmers about overall economic benefits of veterinary treatment over paravets was perceived least potent.

Provision of different paravet and vet cadres has gained recent importance and became a point of debate. It was found that 73.33 percent of veterinarians found the provision of cadre-wise promotion and better remuneration to paravets as the most potent factor. Improving minor veterinary services by relocating unrecognized service providers by providing them suitable identity cards, separate cadres leading to timely promotion and absorption in government services could be very effective (Barbaruah and Samad, 2014). Conflict being indispensable among stakeholders, 60.00 percent of veterinarians perceived a strong need for a sufficient backup mechanism in case conflict between two cadres arises. It was found that 58.33 percent of veterinairans perceived strong need and provision of in-service training of paravets in the supervision of veterinarians. Paravets consult veterinarians in case technical complexity and emergency occur at the field level which they could not handle with the prevailing level of knowledge and expertise. Livestock professionals should work in coordination with farmers, extension professionals to address challenges at the grass-root level. Similar suggestions were proposed by Suvedi et al. (2016). Table 1 revealed that addressing the capacity building needs of paravets, addressing the group formation barriers, and regular contact with veterinarians in the dispensary for updating and supervising their skills by working with them were perceived most potent factor in the supervisory role by $60.00,76.67$, and 35.00 percent veterinarians respectively.

\section{Challenges perceived by paravets in delivery of services for ensuring the satisfaction of farmers in Mathura and Hisar district}

Paravets face various types of challenges in the prompt and efficient delivery of animal husbandry services at farmer's doorstep. It was found that lack of information booklets on breeding and management, lack of standardized curriculum and limited skills in diagnosis, lack of regular training programmes to update knowledge and skill and ethical issues with role obligations were challenges perceived in decreasing order of priority by 55 , $62.50,77.50$ and 47.50 percent paravets of Mathura district respectively (Table 2). Paravets need suitable training and proper coordination with veterinarians for the effective delivery of their services. In this purview, two levels have been designated for them, namely, Level 5 (minimum 1.5-year training) and Level 3 


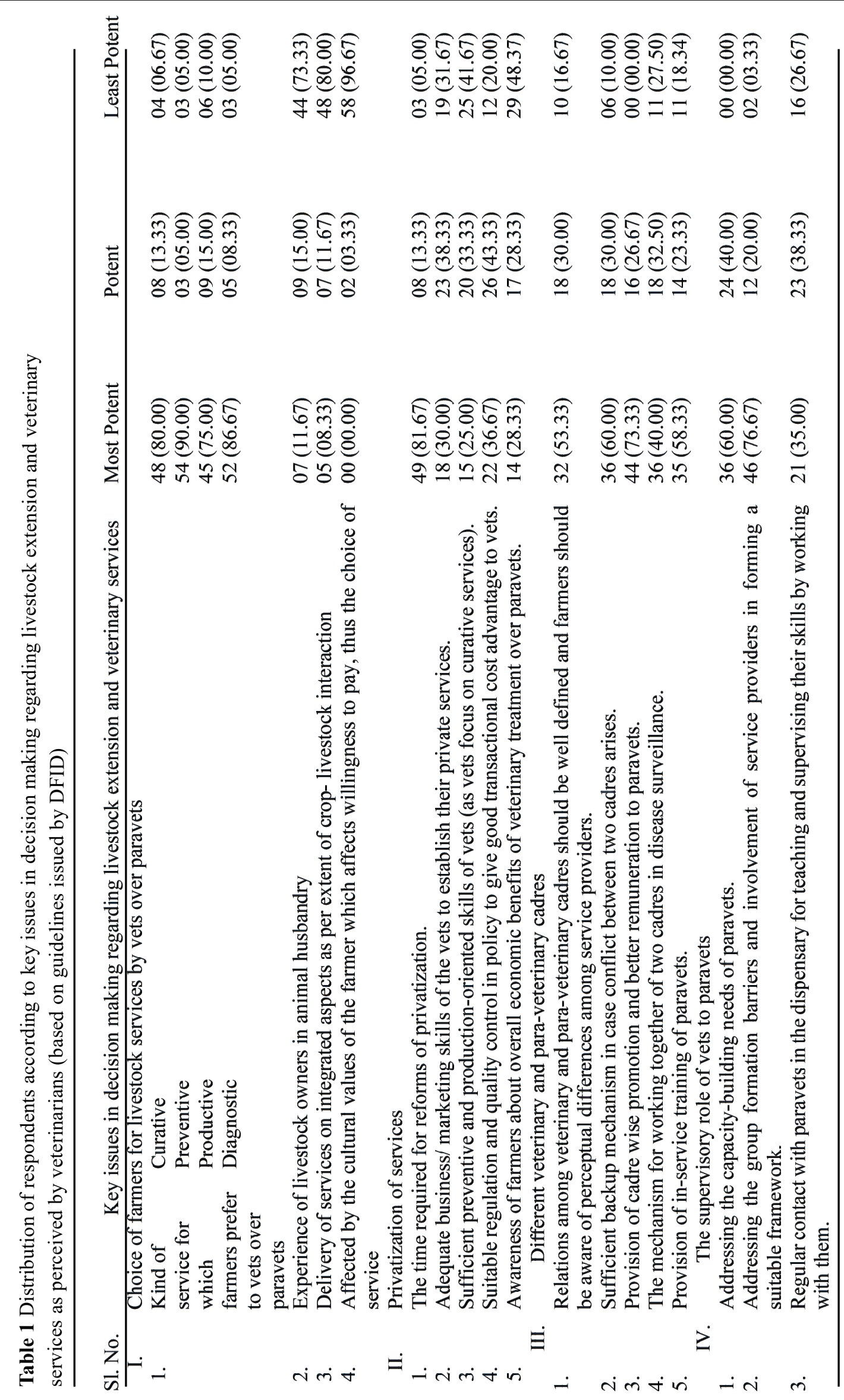


(minimum 45 days) as per the Agriculture Skill Council of India under Pradhan Mantri Kaushal Vikas Yojana (PMKVY) (Barbaruah, 2019). The syllabuses have been designed accordingly, but their utilization throughout the country need to be done to do justice with Level 3 training and practice skills of level 5 training. Similarly, paravets of Hisar district also perceived the above challenges as the topmost challenge in service delivery. Irregular and low income of paravets was perceived as a challenge because it hinders the job morale of the paravets. From table 2, it is clear that the frequency of paravets of Hisar district to perceive challenge in terms of a high degree of potency was relatively lower than paravets of Mathura district. It reveals their readiness, motivation, and good infrastructural, situational, and morale of the paravets in the delivery of service.

Prioritization of challenge depends on the awareness about the issue and its attributing factor with due consideration to the potential of that attributing factors to hinder the work. Food safety of animal products due to overuse of antibiotic drugs was such a challenge for which paravets could not recognize the importance, as result 80 percent paravets of Mathura district and 67.50 percent paravets of Hisar district didn't consider it as a potential challenge. Paravets lack sufficient knowledge and awareness about the drug withdrawal period, as a result of which overuse of antibiotics aggravates the pace of the spread of antibiotic resistance leading to inefficiency of drugs to cure diseases (Landers et al., 2012). Paravets maintain their liquid nitrogen reserve for storing the semen straws and thus it was perceived as the least potent challenge by 42.50 and 65.00 percent paravets of Mathura and Hisar district respectively (Table 2). Non- utilization of laboratories for testing, socio-economic issues of farmers affecting the choice of animal health services, and obtaining over-the-counter treatment by farmer were considered as a potent challenge by $60.00,57.50$, and 42.50 percent paravets of Mathura and 52.50, 27.50, and 30.00 percent paravets of Hisar district respectively.

\section{Challenges faced by paravets in delivery of services for ensured satisfaction of farmers in Jaipur and Ahmadnagar district}

The animal health market of India has been facing the problem of the un-organized market scenario, lack of sufficient manpower for delivery of animal health services, and poor veterinary infrastructure. So there exists a huge prospect and responsibility for the para-veterinary sector to deliver their services with high competency (DAHD \& F, 2012). Thus it becomes imperative to assess the challenges in the delivery of animal health service to make it proficient and efficient. A perusal of Table 3 revealed that lack of standardized curriculum affecting skills and proficiency of paravets, lack of regular training programmes to update knowledge and skill, and ethical issues with role obligations were challenges perceived in decreasing order of priority by $60.00,77.50$, and 52.50 percent of paravets of Jaipur and 67.50, 80.00 , and 60.00 percent paravets of Ahmadnagar district respectively. Paravets perceived that the socio-economic condition of farmers didn't affect the choice of the service provider to a large extent because 57.50 percent of paravets of Jaipur district and 50.00 percent paravets of Ahmadnagar district perceived it as the least potent challenge (Table 3). As the fee charged towards para-veterinary services was reasonable and fixed to farmers irrespective of any socio-economic condition, paravets also recognized that minor- veterinary services don't have much variation in choice for service providers.

Paravets didn't felt that their job requires any advanced and updated technical knowledge in the minor veterinary services. As a result of which they didn't recognize the importance of contact with research institutes and universities. More research on the training needs of paravets may help in building their capacity building on a national level, it should be focused on more standardized training and their professional credentialing at the regional level (FAO, 2011). Non- utilization of laboratories for testing facilities were perceived as a moderately potent challenge by 42.50 percent of paravets of Jaipur and 50.00 percent of paravets of Ahmadnagar district because they felt that basic knowledge of laboratory and equipment were needed as they have the role to bring the animal samples for testing in the nearby dispensary (Table 3).

\section{Barriers perceived by paravets inefficient delivery of minor veterinary services}

Paravets feel certain barriers either policy-related, workplace, or skill-related barriers which prevent them from working efficiently. Irregular and low income and less preference to paravets as compared to veterinarians by large farmers were barriers responsible for low job morale of the paravets with a rank-based quotient value of 92.29 and 84.38 respectively (Table 4). Paravets revealed that in the year they receive good money during premonsoon and pre- wintertime as it was the time of vaccination and deworming schedule. Otherwise, they practice farming for getting continuous and sustained income. Other barriers were the socio-economic condition of farmers affecting choice for AHS provider, inadequate supervision opportunities by vets, and lack of information booklets on breeding and management ranked third, fourth, and fifth with a rank-based quotient value of 79.79 , 73.33 , and 69.58 respectively. These three barriers could be addressed to some extent if the contact between paravets and veterinarians could be regular and supervision by veterinarians could be ensured. Lack of coordination and updated information to paravets was also perceived as an important barrier because in absence of these two things paravets fail to do justice with judicious use of drugs and play their role in persuading farmers with recent technological advancements such as new kits and technologies. Paravets need coordination with veterinarians and perform duties within the boundary of the minor- veterinary services for which they are not equipped or trained (Venkatramaiah and Ahuja (2012). Paravets lose job morale and 


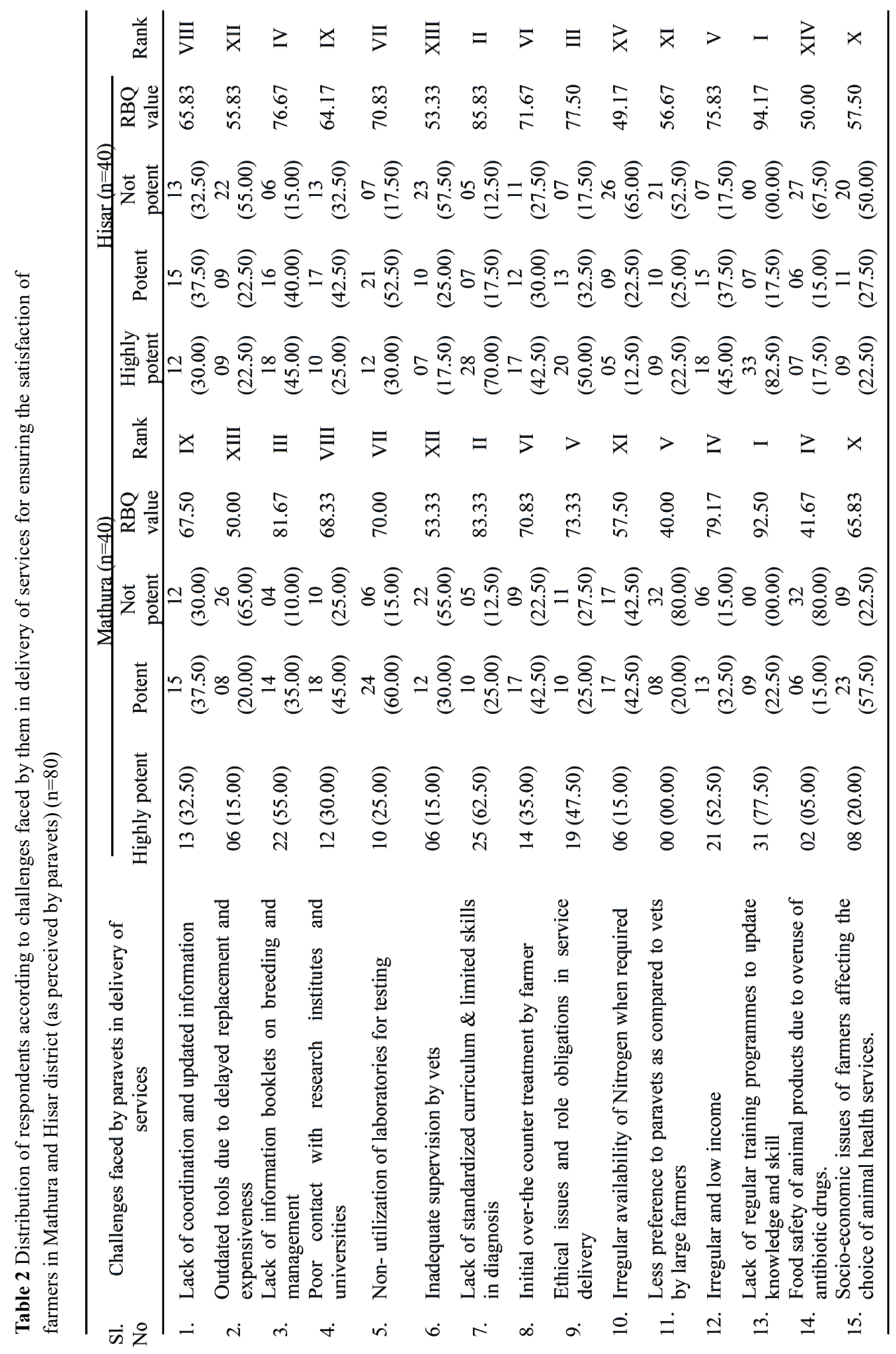




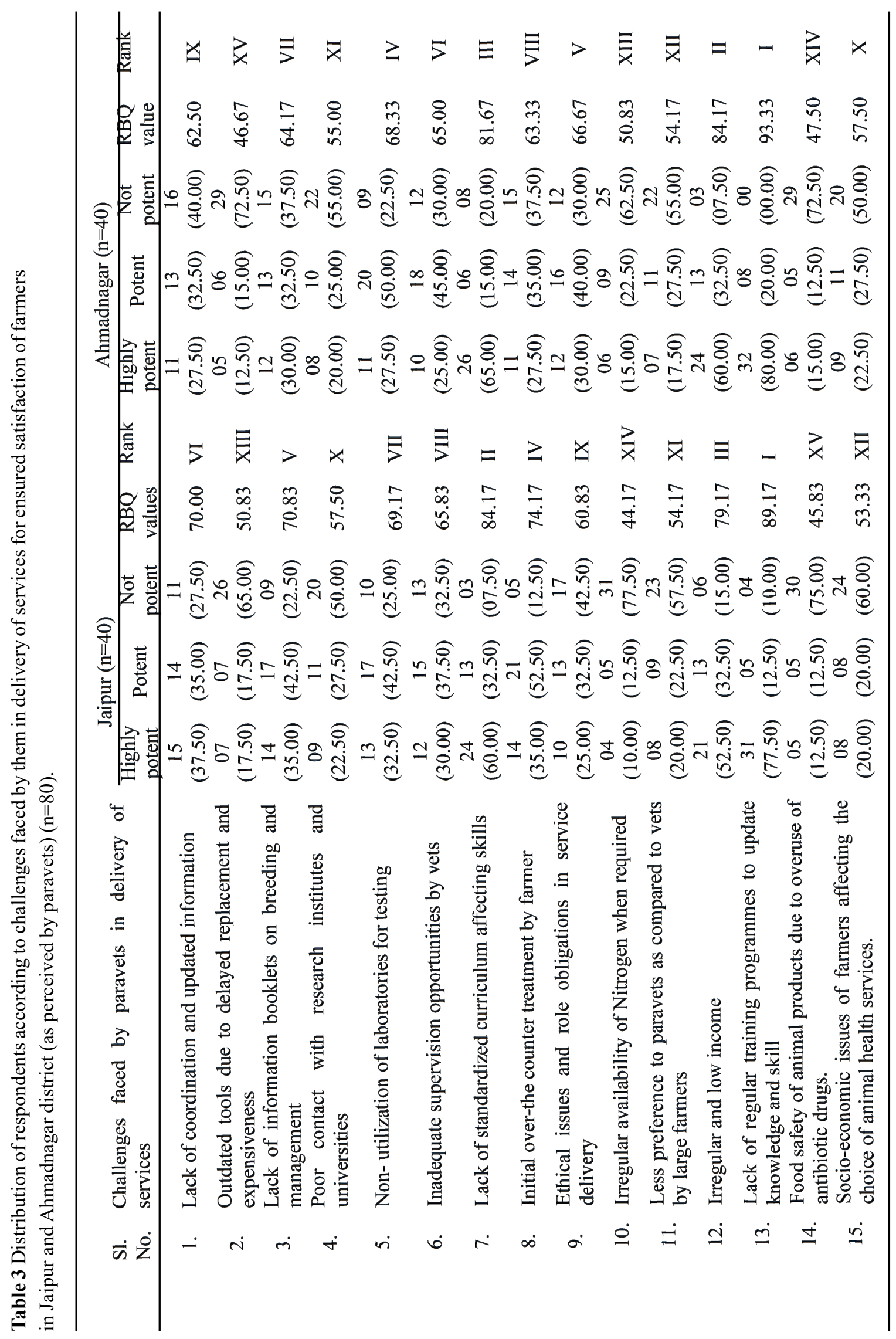


Table 4 Distribution of respondents according to perceived barriers inefficient delivery of para- veterinary services (as perceived by paravets $)(\mathrm{n}=160)$

\begin{tabular}{|c|c|c|c|c|c|c|}
\hline \multirow[t]{2}{*}{ Sl. No. } & \multirow{2}{*}{$\begin{array}{l}\text { Challenges faced by paravets in delivery of } \\
\text { services }\end{array}$} & \multicolumn{3}{|c|}{ Potency } & \multirow[t]{2}{*}{ RBQ value } & \multirow[t]{2}{*}{ Rank } \\
\hline & & High & Medium & Low & & \\
\hline 1 & $\begin{array}{l}\text { Lack of coordination and updated } \\
\text { information }\end{array}$ & $56(27.5$ & $64(35.00)$ & $40(37.50)$ & 70.00 & VI \\
\hline 2 & $\begin{array}{l}\text { Outdated tools due to delayed replacement } \\
\text { and expensiveness }\end{array}$ & $27(16.8$ & $30(18.75)$ & $103(64.37)$ & 50.83 & XIII \\
\hline 3 & $\begin{array}{l}\text { Lack of information booklets on breeding and } \\
\text { management }\end{array}$ & $46(28.7$ & $82(51.25)$ & $32(20.00)$ & 69.58 & V \\
\hline 4 & $\begin{array}{l}\text { Poor contact with research institutes and } \\
\text { universities }\end{array}$ & $37(23.1$ & $56(35.00)$ & $67(41.87)$ & 60.42 & IX \\
\hline 5 & Non- utilization of laboratories for testing & $59(36.8$ & $52(32.50)$ & $49(30.63)$ & 68.75 & VII \\
\hline 6 & Inadequate supervision opportunities by vets & $65(40.6$ & $62(38.75)$ & $33(20.62)$ & 73.33 & IV \\
\hline 7 & $\begin{array}{l}\text { Lack of standardized curriculum \& } \\
\text { limited skills in diagnosis }\end{array}$ & $24(16.0$ & ) $39(23.38)$ & $97(60.62)$ & 51.46 & XII \\
\hline 8 & Initial over-the counter treatment by farmer & $41(25.6$ & $52(32.50)$ & $67(41.87)$ & 61.25 & VIII \\
\hline 9 & $\begin{array}{l}\text { Ethical issues and role obligations in } \\
\text { service delivery }\end{array}$ & $35(21.8$ & $55(34.38)$ & $70(43.74)$ & 59.38 & $\mathrm{X}$ \\
\hline 10 & $\begin{array}{l}\text { Irregular availability of liquid nitrogen gas } \\
\text { when required }\end{array}$ & $21(15.0$ & $40(22.50)$ & $99(62.50)$ & 50.42 & XIV \\
\hline 11 & $\begin{array}{l}\text { Less preference to paravets as compared to } \\
\text { vets by large farmers }\end{array}$ & $104(65$. & 0) 37 (23.13) & $19(11.87)$ & 84.38 & II \\
\hline 12 & Irregular and low income & $127(79$. & 8) $29(18.13)$ & $04(02.50)$ & 92.29 & I \\
\hline 13 & $\begin{array}{l}\text { Lack of regular training programmes to } \\
\text { update knowledge and skill }\end{array}$ & $34(21.2$ & $54(33.75)$ & $72(45.00)$ & 58.75 & XI \\
\hline 14 & $\begin{array}{l}\text { Food safety of animal products due to } \\
\text { overuse of antibiotic drugs }\end{array}$ & $19(11.8$ & $22(13.75)$ & $119(74.38)$ & 45.83 & $\mathrm{XV}$ \\
\hline 15 & $\begin{array}{l}\text { The socio-economic condition of farmers } \\
\text { affecting choice for AHS providers }\end{array}$ & $85(53.1)$ & $53(33.13)$ & $22(13.75)$ & 79.79 & III \\
\hline
\end{tabular}

motivation when they didn't receive money for their efforts because they operate within a very thin margin of income sustainability. Ethical issues and role obligations in service delivery, lack of regular training programmes to update knowledge and skill, and food safety of animal products due to overuse of antibiotic drugs received tenth, eleven, and the fifteenth rank on basis of the weighted mean score.

Pareto analysis and ranking of barriers inefficient delivery of minor veterinary services (as perceived by veterinarians)

Non- exposure to regular training programmes and lack of sufficient skills and proficiency among paravets were prioritized by trainers as the first and second barrier in delivery of paraveterinary services in terms of potency. These barriers have the highest RBQ values 228.33 and 216.67 respectively) (Table 5). Low, irregular, and seasonal fluctuation in income and socioeconomic condition of farmers affecting choice for AHS provider was perceived as a moderate challenge affecting the efficiency and proficiency of paravets in delivery of animal health service. While, veterinarians fail to recognize reward and promotion and dynamic charging by paravets for service rendered to farmers as a potent challenge. The RBQ values for the above challenges were 183.33 and 178.33 , giving second last and last priority to it respectively. Para- veterinary services would proliferate if separate cadres for paravets with timely promotion as well a record of paravets at district level database could be maintained (NAVS, 2018).

The study has also attempted to look at barriers perceived by paravets inefficient delivery of minor veterinary services. Paravets face various constraints in the delivery of prompt and efficient AHS at the farmer's doorstep. To get an overview, a Pareto analysis was done for the above issue. According to this analysis, it was hypothesized that 20.00 percent of the factors were causing 80 percent of the problems. This technique could be useful to find out whether by solving a few issues major bottlenecks, prompt and efficient delivery of minor health service could be executed or not. In the present context, it was well evident that cumulatively almost 7 major factors were contributing to 89.74 percent of the constraints, thereby the hypothesis has been disapproved (Figure 1). Hence, interventions should be planned with a wider focus to overcome barriers to inefficient delivery of minor veterinary services. Thus livestock-related 


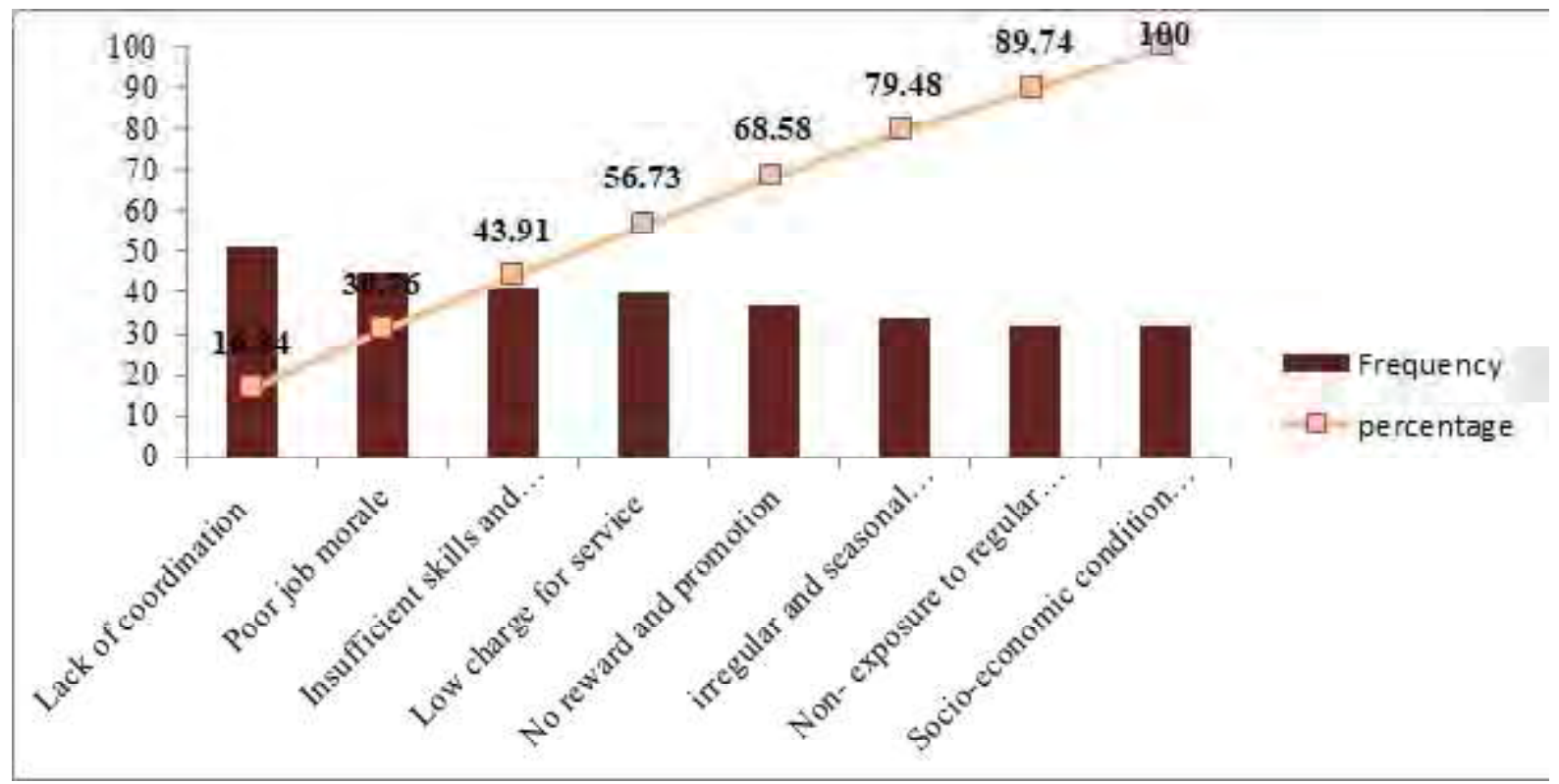

Fig. 1 Pareto Analysis of barriers for paravets inefficient delivery of AHS (in perspective of veterinarians)

Table 5 Distribution of respondents according to barriers perceived by veterinarians inefficient delivery of para- veterinary services $(\mathrm{n}=60)$

\begin{tabular}{|c|c|c|c|c|c|c|}
\hline Sl. No. & $\begin{array}{l}\text { Challenges faced by paravets in } \\
\text { delivery of services }\end{array}$ & $\begin{array}{l}\text { Most } \\
\text { potent }\end{array}$ & Potent & $\begin{array}{l}\text { Least } \\
\text { potent }\end{array}$ & $\begin{array}{l}\text { RBQ } \\
\text { values }\end{array}$ & $\overline{\text { Ranks }}$ \\
\hline$\overline{1}$ & $\begin{array}{l}\text { Lack of coordination between vets } \\
\text { and paravets }\end{array}$ & $19(31.66)$ & $22(36.67)$ & $19(31.67)$ & 200.00 & $\overline{\mathrm{III}}$ \\
\hline 2 & Poor job morale & $18(30.00)$ & $19(31.67)$ & $23(38.33)$ & 191.67 & VI \\
\hline 3 & $\begin{array}{l}\text { Lack of sufficient skills and } \\
\text { proficiency }\end{array}$ & $25(41.67)$ & $20(33.33)$ & $15(25.00)$ & 216.67 & II \\
\hline 4 & $\begin{array}{l}\text { Dynamic charging for service } \\
\text { rendered to farmers }\end{array}$ & $15(25.00)$ & $17(28.33)$ & $28(46.67)$ & 178.33 & VIII \\
\hline 5 & No reward and promotion & $16(26.67)$ & $18(30.00)$ & $26(43.33)$ & 183.33 & VII \\
\hline 6 & $\begin{array}{l}\text { Low, irregular and seasonal } \\
\text { fluctuation in income }\end{array}$ & $18(30.00)$ & $22(36.67)$ & $20(33.33)$ & 196.67 & IV \\
\hline 7 & $\begin{array}{l}\text { Non- exposure to regular training } \\
\text { programmes }\end{array}$ & $26(43.33)$ & $25(41.67)$ & $9(15.00)$ & 228.33 & I \\
\hline 8 & $\begin{array}{l}\text { The socio-economic condition of } \\
\text { farmers affecting choice for AHS pro }\end{array}$ & $\begin{array}{l}15(25.00) \\
\text { ders }\end{array}$ & $27(45.00)$ & $18(30.00)$ & 195.00 & V \\
\hline
\end{tabular}

development intervention for animal health service providers could be very effective (Barbuah, 2017). Almost all the veterinarians had agreed that multiple issues were plaguing AHS and hence demand urgent attention from the policymakers. This reasoning was supported by obtained RBQ values which were not showing a wide variation, thus it indicated equal concern about the various barriers by the veterinarian's inefficient delivery of minor veterinary services. Hence interventions should be planned with a wider focus to resolve these constraints plaguing the delivery of minor veterinary services.

\section{Conclusions}

Strengthening the para-veterinary services, establish proper coordination with peer animal health service providers, and working under professional guidance and support could be effective in overcoming barriers and challenges in the delivery of minor veterinary services. Updating the existing level of knowledge and skill of paravets through various sources, standardized curriculum regular training programmes, and enhanced skills in diagnosis could help overcome the prioritized challenges. Multiple issues plaguing the delivery of animal health services should be solved using holistic and participatory efforts by involving stakeholders. Hence interventions should be 
planned with a wider focus to resolve these constraints plaguing the delivery of minor veterinary services at farmer's doorstep. Overcoming the barriers and challenges along with suitable interventions could increase the accountability and responsibility of paravets to render services with high competency.

\section{Acknowledgments}

The authors acknowledge the Research fellowship and contingency grant provided by UGC to carry out the research smoothly. The infrastructure provided by ICAR-NDRI, Karnal to carry out the research work also deserves high acknowledgment.

\section{References}

$19^{\text {th }}$ Livestock Census. (2012) All India Report. Ministry of Agriculture. Department of Animal Husbandry, Dairying and Fisheries, Krishi Bhawan, New Delhi. Retrieved from: http://dahd.nic.in/sites/default/ filess/Livestock $\% 20 \% 205$.pdf

Agrawal R, Rao DR, Rao BV, Nanda SK, Kumar I (2013) Forecasting manpower requirement in Indian veterinary and animal husbandry sector. Indian J Anim Sci 83: 667-672

Anonymous (2018) Outlook of Indian Animal Health Market. Benison Media. Retrieved on $9^{\text {th }}$ February 20121 from: http:// benisonmedia.com/outlook-of-indian-animal-health-market/

Barbaruah IM (2017) Scope for private veterinarians in India. Vet Helpline India Pvt Ltd. Retrieved on $9^{\text {th }}$ February 2021 from https:// www.vethelplineindia.co.in/scope-for-private-veterinariansin-india/

Barbaruah MI (2019) Changing face of Paraveterinary services in India: The roadmap for strengthening of services. 27th Bi-ennial conference of All Assam Veterinary Field Assistant Association, Nagoan. 4- $6^{\text {th }}$ February 2019

Channappagouda B, Sasidhar PV (2018) Livestock Service Delivery in Karnataka -Perceptions and Reflections of Veterinarians. Int J Livest Res 8: 172-181

DAHD \& F (2012) Report of the Working Group on Animal Husbandry \& Dairying, $12^{\text {th }}$ Five Year Plan. Submitted to Planning Commission, Government of India. New Delhi: 4- 12. Retrieved on $10^{\text {th }}$ February 2021 from: https:/niti.gov.in/planningcommission.gov.in/docs/ aboutus/committee/wrkgrp12/agri/AHD_REPORT_Final_rev.pdf

DAHD \& F (2018) Annual Report 2017- 18. Department of Animal Husbandry, Dairying \& Fisheries. Ministry of Agriculture \& Farmers Welfare. Government of India. Retrieved on $9^{\text {th }}$ February from: http://dadf.gov.in/sites/default/filess/annual_report_17-18.pdf

Hopker A, Pandey N, Dhamorikar A, Hopker S, Gautam P, Pandey S, Sargison N (2018) Delivery and evaluation of participatory education for animal keepers led by veterinarians and para-veterinarians around the Kanha Tiger Reserve, Madhya Pradesh, India. PloS one 13: 124

Landers TF, Cohen B, Wittum TE, Larson EL (2012) A review of antibiotic use in food animals: perspective, policy, and potential. Public health reports 127: 4-22

Mirajkar PP, Kumar S, Singh YP (2011) Preference of service providers for the veterinary service-a case study of Sangli District of Maharastra state, India. Vet World 4:106

NAVS (2018) Paravet Regulation in India. Policy Paper No. 4, National Academy of Veterinary Sciences (India), New Delhi

NDDB (2015) Animal health scenario in India. Animal Husbandry Group, National Dairy Development Board, Anand, Gujrat: 1-13. Reterieved on $9^{\text {th }}$ Febraury 2021 from: https://www.dairyknowledge.in/sites/ default/files/animal_health_in_india_.pdf
NDDB (2019) Per capita availability of Milk by States/UTs. Animal Husbandry Group, National Dairy Development Board, Anand, Gujrat. Retrieved from: https://www.nddb.coop/information/stats/ percapitavail

Rama RD, Agrawal R, Nanda SK, Awasthi IC, Joshi GP, Bhattacharya S,Kumar ID (2011) Assessment of Future Human Capital Requirements in Agriculture and Allied Sectors. NAIP Project Report, National Academy of Agricultural Research Management, Hyderabad and Institute of Applied Manpower Research (Now National Institute of Labour Economics Research and Development), India: 410.

Rao SVN, Sulaiman RV, Natchimuthu K, Ramkumar S, Sasidhar PV (2015) Improvement of veterinary services delivery in India. Revue Scientifique et Technique 34: 767- 777

Saadi B, Isabelle T (2015) Quality Community Animal Health Arrangements.Agronomes et Vétérinaires Sans Frontières: 1-78

Sabarathnam VE (1988) Manual on field experience training for ARS scientists, National Academy Research Management, Rajendranagar, Hyderabad, Telangana, India, 21

SAPPLPP (South Asia Pro-Poor Livestock Policy Programme) (2012) Watershed development and livestock rearing: experiences and learning from the watershed organisation trust in Maharashtra, India. SAPPLPP, New Delhi: 56.

Sasidhar PVK, Reddy PV 2012. SWOT analysis of veterinary and animal science education in India: Implication for policy and future directions. J Agric Edu Extension 18: 387-407

Shubeena S, Bhattacharjee S, Raj S (2019) Assessment of Core Competencies of Livestock Extension Professionals of Jammu and Kashmir State of India Discussion Paper 8. - Centre for Agricultural Extension Innovations, Reforms, and Agripreneurship, MANAGE, Hyderabad: 1- 70. Retrieved on $10^{\text {th }}$ February from: https:/www.manage.gov.in/ publications/discussion\%20papers/MANAGE-Discussion\%20Paper8.pdf

Suvedi M, Kaplowitz M (2016) What every extension worker should know: Core competency handbook. Urbana Champaign, IL: USAIDMEAS: 7-22

Venkatramaiah P, Ahuja V (2005) Minor Veterinary Services in Andhra Pradesh: Stakeholder Consultations and Expert Group Deliberations. Pro-Poor Livestock Policy Initiative of FAO, Capitalization of Livestock Program Experiences India of SDC and Government of Andhra Pradesh (GoAP). Retrieved on $9^{\text {th }}$ February 2021 from: www. fao. org/ag/againfo/projects/en/pplpi/research. html Warburton H, Blake R, Coupe S, Pasteur K, Phillips E (2011) Bridging the gap between resource-poor farmers and extension services: the role of community based extension systems. In International Conference on Innovations in Extension and Advisory Services, Nairobi, November: $15-18$ 